\title{
OS CALDEIRÕES DE LAJEDO/PE NO CONTEXTO DE SUA PAISAGEM GEOMORFOLÓGICA ATRAVÉS DA VISÃO SISTÊMICA
}

\author{
Jeovanes Lisboa da Silva Filho ${ }^{1}$
}

\section{Maria Betânia Moreira Amador ${ }^{2}$}

\begin{abstract}
RESUMO
O trabalho de iniciação cientifica que se apresenta conta com bolsa CNPq através do Edital 20142015 e está sendo desenvolvido no município de Lajedo-PE, onde o mesmo se vincula a um projeto de maior dimensão, o qual vincula a seleção do bolsista de forma que o selecionado trabalhe no seu município de origem e residência procurando-se seguir a orientação da "Topofilia". Está-se trabalhando um compartimento geomorfológico considerado patrimônio denominado de Caldeirões devido à concavidade de suas rochas que acumulam água e que apresentam um grande significado devido ao seu contexto histórico para Lajedo e região, podendo assim devido a sua beleza natural e valor cultural promover até a visitação turística. Logo, um dos objetivos é o fato de colocar os Caldeirões no contexto ambiental do município e entender como a população os percebe. Em termos metodológicos segue-se as leituras e orientação sistêmica para a compreensão da complexidade da paisagem em estudo, e poder entendê-la em seus variados aspectos de maneira integrada. Visitas in loco também são realizadas, bem como, registros fotográficos do momento atual, bem como busca-se encontrar fotos antigas para se ter parâmetros comparativos da referida paisagem. Os resultados até então obtidos permitem verificar, mesmo que previamente, a falta de valorização e importância dos Caldeirões para a memória coletiva do município, principalmente no âmbito da juventude. Pretendese, ainda, contribuir positivamente para que as pessoas pensem nesse lugar agregando valor e também colaborar com o poder público em sua gestão municipal por meio de propostas que promovam a sustentabilidade do lugar.
\end{abstract}

PALAVRAS-CHAVE: Sistemismo. Caldeirões. Paisagem.

\footnotetext{
${ }^{1}$ Graduando do curso de Licenciatura em Geografia pela Universidade de Pernambuco - Campus Garanhuns - bolsista do PIBIC CNPq através do Edital 2014/2015 - Integrante do (GESSANE) Grupo de Estudos Sistêmicos do Semi-Árido do Nordeste. E-mail: jeovanelisboa@hotmail.com.

${ }^{2}$ Doutora em Geografia pela UFPE e Professora Adjunta da Universidade de Pernambuco - Campus Garanhuns atuando no curso de Geografia e líder do (GESSANE) Grupo de Estudo Sistêmicos do SemiÁrio do Nordeste. E-mail betaniaamador@yahoo.com.br.
} 


\title{
ROCKY CAULDRONS OF LAJEDO IN THE CONTEXT OF GEOMORPHOLOGICAL LANDSCAPE THROUGH SYSTEMIC VISION
}

\begin{abstract}
This scientific research work has a scholarship by National Council for Scientific and Technological Development (CNPq), through the notice 2014-2015 and is being developed at Lajedo city, Pernambuco, Brazil, where it has a link to a larger project that binds the student to work on his hometown and city who lives following the orientation of "Topofilia". Is being worked a geomorphological compartment considered heritage known as Cauldrons because of their rocky concavities that accumulate water and has a great significance because of their historical context for Lajedo and region, this way it could be used as touristic point because of the natural beauty and cultural value. One of the targets is to put the rocky cauldrons on the environmental context of the city and know how the population perceive them. In methodological terms, it follows the reading and the systemic orientation to the comprehension of studied complexity landscape, and be able to understand it on their miscellaneous aspects by an integrated approach. We made local visits, as well as photographic records of the current moment, are made searches to find old pictures to have comparative parameters of the said landscape. The obtained results allows you to check, same as previously, the lack of appreciation and relevance of the rocky cauldrons to the collective memory of the people, especially in the field of youth. We intend to contribute positively to make people thinks of this place adding value and collaborating with the public power as the municipal management by proposes that could increase the sustainability of the place.
\end{abstract}

Keywords: systemism, cauldrons, landscape.

\section{LOS CALDEROS ROCOSOS EN EL CONTEXTO DEL PAISAJE GEOMORFOLÓGICO ATRAVÉS DE LA VISIÓN SISTÉMICA}

\begin{abstract}
Este estudio tiene una beca dada por el Consejo Nacional de Desarrollo Científico y Tecnológico (CNPq) por el aviso 2014-2015 y se está haciendo en la ciudad de Lajedo, Pernambuco, Brasil, donde la investigación tiene enlace con un proyecto más amplio asociando al estudiante para que trabaje en ciudad de nacimente o donde vive actualmente, siguiendo las directrices de la topofilia. Está siendo trabajado un compartimiento geomorfológico considerado patrimonio, debido a sus cavidades rocosas y a su capacidad de almacenamiento de agua este compartimiento es conocido como "calderos rocosos" y tiene importancia debido a su contexto histórico para Lajedo y la región, por lo que podría ser utilizado como una atracción turística debido a su belleza natural y valor histórico. Uno de los objetivos es poner los calderos rocosos en el contexto ambiental de la ciudad y descubrir la percepción de la población. Metodológicamente, se sigue la lectura y la orientación sistémica de la comprensión del paisaje estudiado para enfender los aspectos diversos a través de un abordaje integrado. Fueron hechas visitas en el sitio, así como registros fotográficos del momento, se realizaron investigaciones buscando fotografías antiguas para llegar a parámetros de comparación del paisaje. Los resultados obtenidos nos muestran que anteriormente había la falta de apreciación y relevancia de los calderos rocosos a la memoria colectiva de las personas, especialmente a la de los jóvenes. Tenemos la intención de contribuir con la valoración de este sítio con el poder público y la administración de la ciudad con el fin de desarrollar la sostenibilidad del sitio.
\end{abstract}

PALABRAS-CLAVE Sistemismo. Calderos. Paisaje. 


\section{INTRODUÇÃO}

O Nordeste brasileiro dispõe de uma grande diversidade de quadros naturais, nos quais se inserem as diversas paisagens da Região Agreste de Pernambuco que podem ser consideradas como das mais dinâmicas por estarem situadas numa zona de transição entre a Mata e o Sertão, apresentam belezas únicas, típicas dessa zona fisiográfica e, entre elas as de caráter geológico-geomorfológicas, ainda pouco estudadas pela comunidade acadêmica/cientifica. Essas paisagens apresentam um grande potencial para promover, quem sabe até o turismo, sendo assim, são dignas de estudos que compreendam de maneira integrada a sua complexidade e para isso entende-se ser importante utilizar uma abordagem sistêmica. $\mathrm{O}$ presente trabalho versa sobre o estudo da paisagem geomorfológica dos Caldeirões em Lajedo-PE, onde o mesmo se vincula a um projeto de maior dimensão conduzido pela orientadora desse trabalho de iniciação científica.

Objetivou-se analisar a paisagem geomorfológica dos Caldeirões em Lajedo PE sob uma perspectiva sistêmica, e identificar a área onde os mesmos se encontram, bem como situá-los no contexto ambiental do município e perceber como os habitantes de Lajedo se relacionam com os mesmos. Ademais, julga-se importante, também, fazer uso da interdisciplinaridade inerente à ciência geográfica fazendo uso do sistemismo que vai se coadunar, por sua vez, com o pensamento complexo ou teoria da complexidade estudada e defendida por Edgar Morin desde a década de 1970.

O artigo faz uma breve caracterização do município em estudo e do objeto que está sendo trabalhado por essa sub-pesquisa com bolsa PFA/CNPq possibilitando ao aluno bolsista do Curso de Licenciatura em Geografia da UPECampus Garanhuns, geograficamente posto em seu lugar de origem e residência realizar estudos em sua cidade, baseando-se na "Topofilia" de Yi Fu Tuan, que nada mais é do que o elo afetivo da pessoa com o meio físico e o seu lugar, dando oportunidade para que o autor desse trabalho desenvolva sua pesquisa da melhor maneira possível e que possa contribuir positivamente com propostas que colaborem, oportunamente, com o poder público em gestão municipal. 
Os procedimentos metodológicos, pautam-se no levantamento bibliográfico, como também ida a campo e diálogo com os moradores in loco, para compreender como os mesmos percebem esse local, fotografias também foram importantes, para registrar o momento atual, bem como o resgate de algumas fotografias antigas. Os resultados até aqui alcançados por essa pesquisa oferecem reflexões que interessam à todos, principalmente os Lajedenses e Agrestinos em geral.

\section{PRESSUPOSTOS TEORICOS-METODOLOGICOS}

"A visão sistêmica, como forma de abordagem dos fenômenos tem emergido no contexto de várias ciências, na tentativa de se apresentar como uma alternativa ao modo reducionista, disjuntivo, separador das partes" (AMADOR, 2011, p. 89). Nesse sentido, a visão sistêmica se coaduna com a interdisciplinaridade presente na geografia, na qual vai ser possível refletir os problemas encontrados de maneira organizada. Dessa forma, possibilita também, ter-se um entendimento de forma integrada fazendo relações entre o homem e a natureza, a visão sistêmica em qualquer ótica de estudo é de fundamental importância para a análise do objeto estudado principalmente quando se trata de estudos ambientais em que a Geografia tem muito a contribuir, uma vez que é necessária uma análise de variados pontos que se interligam, e essas inter-relações são importantes, e contribuem para elaboração de um trabalho mais consistente e integrado. Ainda abordando o pensamento sistêmico Amador (2007) nos faz refletir sobre essa temática, onde ela ressalta que:

\footnotetext{
Pensar e agir sistemicamente, em qualquer área de estudo, requer refletir problemas sob o aspecto da ordem, da organização, da totalidade, entre outros. Logo, são abordagens que fogem ao tradicional reducionismo da ciência que, busca entender os fenômenos, prioritariamente, pelo observável e pelo testável, fundamentado sobremaneira na física e na matemática, vindo a contribuir ao longo do tempo na extrema especialidade que esquece, ou não encontra espaço para entender o todo, ficando retido, apenas, na questão da causa e efeito de forma linear (AMADOR, 2007, p. 26).
}

No que se refere à reflexão de problemas a serem analisados numa abordagem sistêmica percebe-se que há avanços de compreensão, principalmente quando se faz a conexão com a literatura disponível contribuindo para uma melhor articulação entre a realidade e a utopia de ver a referida paisagem dos Caldeirões 
num outro patamar de valorização tanto pela comunidade local, quanto pelo município. Assim, com base em Suertegaray (2005, p. 41), com a qual se concorda, no âmbito da Geografia "não se deve recorrer ao sistemismo como uma teoria interpretativa da natureza, mas sim como um caminho analítico - um método". Por isso compreende-se ser importante a utilização da visão sistêmica nesse trabalho, onde sabe-se que a mesma possui uma forte relação com o pensamento complexo, ambos estão sempre interligados e se coadunando um com o outro, e que dessa forma possibilita a compreensão da dinâmica presente em estudos como o apresentado para poder entender a paisagem geomorfológica e sua complexidade. Dentro desse contexto, observa-se a necessidade, também, de expor um conceito do pensamento complexo:

\begin{abstract}
Morin entende que o pensamento complexo é um tipo de pensamento que não separa, mas une e busca as relações necessárias e interdependentes de todos os aspectos da vida. E, para isso é necessário conhecimento e contextualização do fenômeno que se quer estudar, inserindo-o num quadro mais abrangente sem esquecer que 0 ato de "contextualizar exige a realização de operações lógicas contrárias às de disjunção e redução, contrárias às operações de simplificação que produzem uma simplicidade atomizada (VASCONCELLOS, 2003, p.113 citado por AMADOR, 2013, p. 24).
\end{abstract}

Como destaca Vasconcellos, Morin diz que a complexidade vai ordenar os fenômenos, ou seja, relacionar, fazer relações, e não explicar um fenômeno focando em apenas um objeto, fugindo, assim, daquele modo de pensar tradicional cartesiano e positivista, mas sim procurando a maneira mais ampla, possível e integrada para poder de fato compreender o que está sendo trabalhado e poder colocá-lo de maneira clara, por isso é importante também a interdisciplinaridade. Importa considerar, ainda, o conceito de paisagem, nessa perspectiva entende-se que:

\footnotetext{
A paisagem não é a simples adição de elementos geográficos disparatados. É uma determinada porção do espaço, resultado da combinação dinâmica, portanto instável, de elementos físicos, biológicos e antrópicos que, reagindo dialeticamente uns sobre os outros, fazem da paisagem um conjunto único e indissociável, em perpétua evolução (BERTRAND 1971, p. 2 citado por AMADOR, 2014, p. 26).
}

Ainda procurando-se conceituar paisagem, Yi- fu Tuan (1980), considera que a paisagem veio adquirir um significado valioso no final do século XVI, assim na sua obra "Topofilia" ele ressalta que: 
A paisagem chegou a significar um panorama visto de um determinado ponto. Depois, foi à representação artística desse panorama. Paisagem também foi o pano de fundo de retratos oficiais; o "cenário" de uma "posse". Com esse significado a palavra se integrou inteiramente no mundo do faz de conta. (TUAN, 1980, p. 153).

Por sua vez, o geógrafo Ab'Saber (2003, p. 09) em sua obra intitulada: Domínios de Natureza no Brasil: Potencialidades Paisagísticas traz o seguinte entendimento sobre paisagem: "a paisagem nada mais é do que uma herança, uma herança em todo sentido da palavra: herança de processos fisiográfico e biológicos, e patrimônio coletivo dos povos que historicamente as herdaram".

Outro conceito que também deve ser destacado nesse trabalho é o de lugar, e sabe-se que o lugar é uma das categorias de análise da Geografia onde Yi Fu Tuan em sua obra Espaço e Lugar: a perspectiva da experiência, apresenta o seguinte conceito:

O lugar é um mundo de significado organizado. É essencialmente um conceito estático. Se víssemos o mundo como processo, em constante mudança, não seriamos capazes de desenvolver nenhum sentido de lugar (TUAN, 2013 p. 72).

Esse mesmo autor, na mesma obra (2013, p. 82), ainda considera que: "O lugar pode adquirir profundo significado para 0 adulto mediante 0 continuo acréscimo de sentimento ao longo dos anos".

Cabe considerar que o sistemismo e a complexidade são os aparatos teóricos e metodológicos utilizados nesse trabalho, por compreender a sua importância nos estudos ambientais e na análise integrada da paisagem, a paisagem também é uma das categorias de análise da Geografia e talvez aquela dita mais dinâmica, em constante evolução como bem destaca Bertrand (1971). Tem-se ainda, o lugar, e esse de grande valor, trabalhado pelo geógrafo Yi Fu Tuan.

\section{O MUNICIPIO DE LAJEDO-PE}

Esse município (Figura 01) está localizado na Região Agreste de Pernambuco, especificamente na Microrregião de Garanhuns situando-se, ainda, no semiárido nordestino. 
Figura 01- Localização do Município de Lajedo-PE

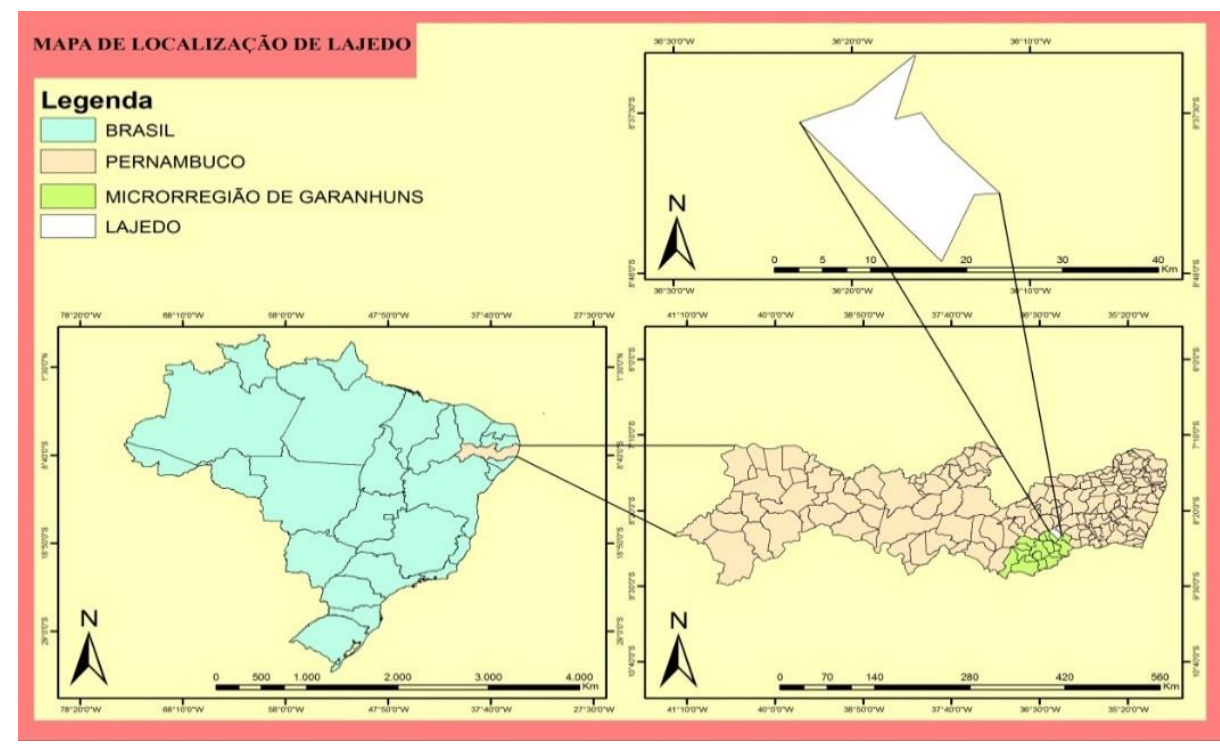

Fonte: Adaptado por: Renilson Ramos e J. Lisboa, 2014.

O referido município possui um clima que varia do subúmido ao semiárido situando-se, ainda, numa área de transição entre a zona fisiográfica do Sertão e a Zona da Mata. Seu relevo apresenta características planas sendo levemente ondulado e está localizado na área central do Planalto da Borborema que se estende do sul de Alagoas ao Rio Grande no Norte. Segundo o Instituto Brasileiro de Geografia e Estatística - IBGE (2012), o município dispõe de aproximadamente 36.628 habitantes, desses 26.395 estão situados na zona urbana e 10.223 na zona rural distribuídos em uma área total de $189,1 \mathrm{Km}^{2}$ e com uma densidade demográfica de 193,70 há. $/ \mathrm{km}^{2}$ apresentando, ainda, uma altitude de, aproximadamente, 661 metros. Em termos de estradas, Dias (2013, p.116) ressalta que é através das rodovias BR 232, BR, 432, PE 170 e PE 180 que se tem acesso ao município de Lajedo que dista $191,1 \mathrm{Km}$ da capital do estado.

\section{CARACTERIZAÇÃO DOS CALDEIRÕES EM LAJEDO-PE}

Com base na literatura consultada tem-se que a formação geológicogeomorfológica que compõe a paisagem de Lajedo-PE, data do período Pré- 
Cambriano ressaltando-se que a mesma apresenta rochas metamórficas que são aquelas que resultam de profundas modificações sofridas pelas rochas preexistentes (ígneas ou magmáticas) devido, principalmente, às bruscas variações de pressão e temperatura (JATOBÁ; CASTRO, 2006, p. 91). O mesmo autor, ainda destaca que as rochas metamórficas são de vários tipos, as mais frequentes que ocorrem no nordeste brasileiro são do tipo Gnaisse apresentando como características: textura grossa e geralmente bem orientada, a cor variando de cinza, róseo ou quase preto, sendo assim pode-se conjecturar que a formação geológico-geomorfológica dos Caldeirões em Lajedo é do tipo metamórfica gnaisse, pois suas características parecem corresponder ao descrito na literatura (Figura 02).

Figura 02 - Caldeirões de Lajedo-PE

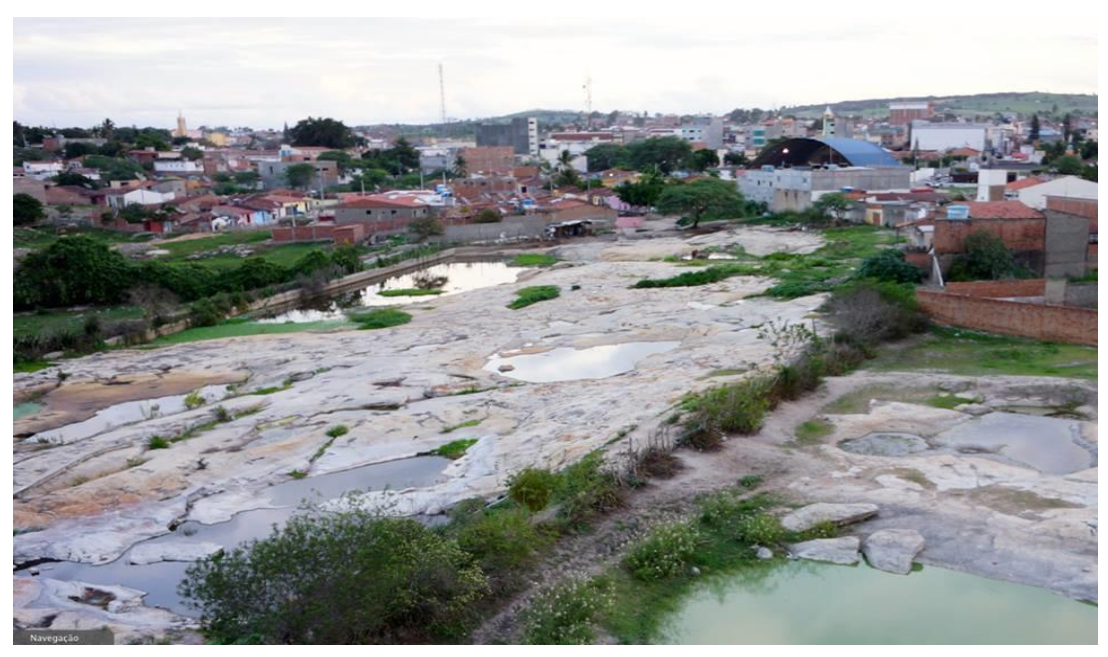

Fonte: ONG curta os Caldeirões, 2012

Nessa figura 02 pode-se visualizar com maior propriedade a rocha principal, na qual está localizada na área pública pertencente a prefeitura municipal. É possível identificar onde de fato apresenta concavidades devido ao acúmulo de água e ter uma visão mais integrada da extensão rochosa. Com relação à área dos Caldeirões, sabe-se que a mesma é catalogada pelo Plano de Preservação dos Sítios Históricos do Interior (PPSHI) como patrimônio cultural, como está citado abaixo.

A área dos caldeirões de Lajedo é catalogada pelo Plano de Preservação dos Sítios Históricos do Interior (PPSHI) e o Plano Diretor de Lajedo a classifica como área de proteção ambiental (APA), com lei especifica para assegurar sua preservação e conservação (DIAS, 2013, p.74). 
No entanto percebe-se que na atualidade "Os Caldeirões" não estão devidamente preservados como pretende o (PPSHI). Nota-se que a maioria da população não apresenta um sentimento de pertencimento para com essa localidade, apesar de que alguns cidadãos mais antigos que residem no seu entorno até reconhecem a importância dos Caldeirões, mas em sua maioria, principalmente os mais jovens, percebe-se que eles não tem essa mesma percepção. Nesse contexto toma-se o pensamento de Tuan (2013) que coloca a seguinte reflexão referindo-se ao lugar:

O espaço fechado e humanizado é lugar. Comparado com o espaço, o lugar é um centro calmo de valores estabelecidos. Os seres humanos necessitam de espaço e lugar. As vidas humanas são um movimento dialético entre refúgio e aventura, dependência e liberdade. (TUAN, 2013 p. 72).

Como bem destaca o esse autor, os seres humanos precisam de espaço e de lugar, pois os mesmos apresentam uma série de valores e significados, uma vez que a vida humana é um movimento dialético que apresenta variações com o decorrer do tempo dentro de um determinado espaço e lugar. As pessoas também precisam de um lugar para se sentirem protegidas como também precisam do espaço, e esse irá permitir uma maior liberdade. Agora as pessoas precisam conhecer esse lugar e agregar valor e ele, no caso aqui estudado "Os Caldeirões", e que esse lugar lhe proporcione sentimento, amor, segurança ou até mesmo liberdade, porém percebese que no tempo presente não há uma relação muito forte por parte da maioria dos moradores de Lajedo-PE, principalmente os mais jovens, tendo em vista que essa nova geração não recebeu nenhuma informação através da educação sobre a importância dessa paisagem geomorfológica considerada patrimônio histórico e cultural da cidade. No sentido de amor e pertencimento ao lugar (Tuan, 1980) nos faz refletir trazendo à tona a "topofilia" que apresenta a seguinte conotação:

A palavra "topofilia" é um neologismo, útil quando pode ser definida em sentido amplo, incluindo todos os laços afetivos dos seres humanos com o meio ambiente material. Estes diferem profundamente em intensidade, sutileza e modo de expressão. A resposta ao meio ambiente pode ser basicamente estética: em seguida, pode variar do efêmero, prazer que se tem de uma vista, até a sensação de beleza, igualmente fugaz, mas muito mais intensa, que é subitamente revelada. A resposta pode ser tátil: o deleite ao sentir o ar, água, terra. Mais permanentes e mais difíceis de expressar, são os sentimentos que temos para com um lugar, por ser o lar, o locus de reminiscências e o meio de se ganhar a vida (TUAN, 1980, p. 107). 
A "Topofilia" nos remete a pensar em nosso lugar de origem, com o qual temos uma identidade, e a possibilidade de conhecimento cientifico, a troca de saberes e a inserção participativa na gestão ambiental municipal poderá tornar a agregação de valor a esse lugar, de forma ampla, bem mais fácil e viável quando o conhecemos e o amamos.

\section{PROCEDIMENTOS METODOLOGICOS}

Em termos metodológicos, para o desenvolvimento do referido trabalho, inicialmente buscou-se referências bibliográficas da temática proposta, como também buscou-se consultar qualquer documento ou escrito, que se refira aos Caldeirões. Também foram realizadas entrevistas com a população que reside no entorno do local estudado procurando elementos para perceber como eles interagem com essa formação geológico-geomorfológico, tão marcante na paisagem local e regional. Visitas in loco também foram realizadas, através da abordagem sistêmica coadunando-se com a complexidade do objeto em estudo. Essas visitas permitiram conseguir uma riqueza de informações que estão sendo discutidas e escritas em gabinete. Nesse contexto, o uso de fotografias antigas e da atualidade foram pertinentes para fazer uma comparação da paisagem que se apresenta em análise.

\section{RESULTADOS E DISCUSSÕES}

Como considerações preliminares pode-se ressaltar impactos de ordem física / ambiental que resultam em danos na paisagem aqui estudada, principalmente por deposição inadequada de lixo dos mais diversos tipos, desde os industriais aos residenciais, tendo em vista que o riacho Doce e o riacho Prata que perpassam toda área urbana do município, também perpassam nos Caldeirões e levam consigo uma grande parcela de poluição que contribui para contaminação das águas presentes nas concavidades, bem como gera uma série de riscos à saúde da população que vive em comunidade na área em apreço circundando-a. Outro indicativo negativo que se percebeu foi à falta de valorização por parte da maioria da população, em relação importância dos "Caldeirões" para o município ressaltando-se, também, as 
várias construções de casas e estabelecimentos comerciais, aparentemente sem respeito a esse patrimônio municipal, já estabelecido como pode ser visto na figura 03.

Figura 03 - Casas com os quintais para os Caldeirões

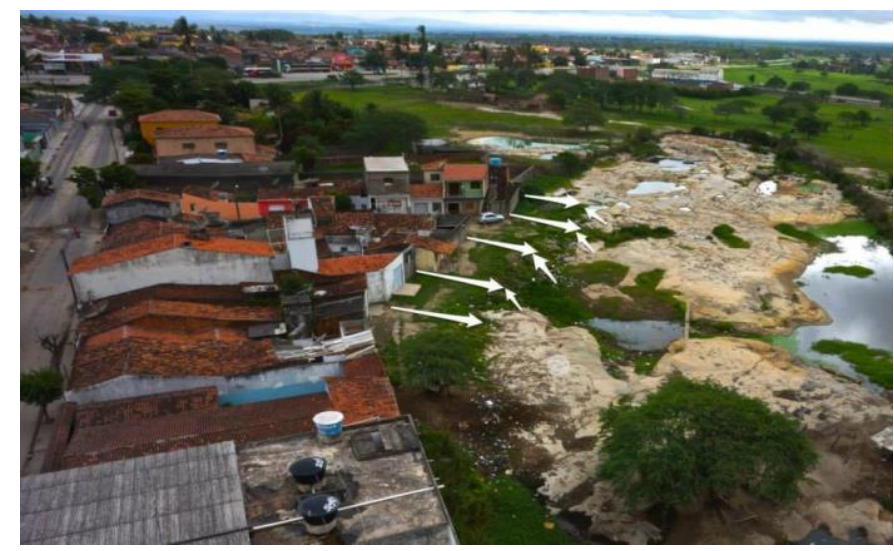

Fonte: ONG Curta os Caldeirões, 2012

A figura 03 mostra, com propriedade, que as construções residenciais, de um modo geral, estão de costas para os Caldeirões, talvez se no lugar dessa formação rochosa fosse uma praia, o processo seria o inverso. À esquerda da mesma foto 03 tem-se a Avenida Presidente Kennedy, uma das principais entradas que dá acesso ao centro da cidade, prefeitura, fórum, escolas e a direita, encontra-se a rocha principal dos Caldeirões. Acredita-se, também, não haver esforço educativo em relação a esse patrimônio por parte dos munícipes, há presença de animais soltos no lugar diariamente, uma vez que encontra-se totalmente aberto. Não apresenta também nenhuma iluminação, o que causa até medo na população do entorno, pois um lugar aberto, abandonado e sem iluminação, no centro da cidade, pode tornar-se perigoso.

Refletindo-se sobre tudo isso, nota-se na história da cidade, como também em relatos de moradores e artistas locais que nos seus primórdios, quando Lajedo ainda era uma pequena vila por volta de 1940 chegando até 1980, já como cidade, a principal fonte de água para abastecer a população era os Caldeirões, para as mais diversas utilidades. Sendo assim, os caldeirões e suas águas eram vistos como algo precioso pela a população, servia até de ponto turístico, área de lazer, encontro de casais, amigos e até mesmo piqueniques, a população fazia até mutirão para a limpeza do local, conforme consta nas figuras 04 e 05. 
Figura 04: moradores em mutirão de limpeza.

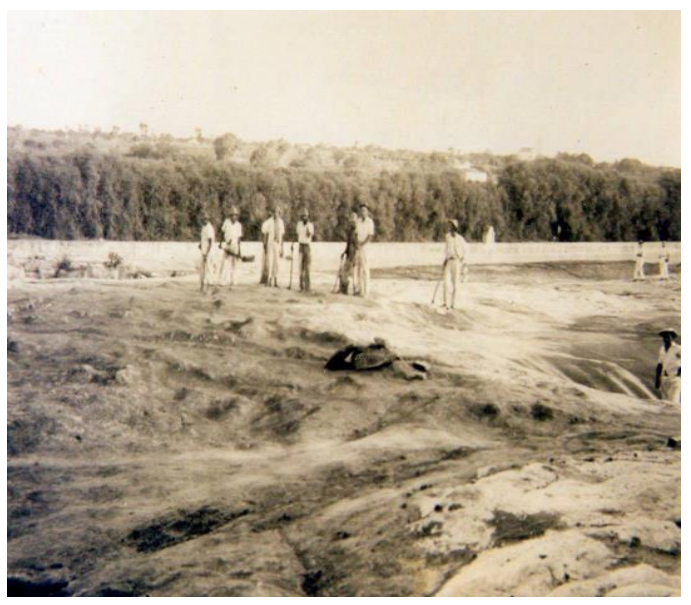

Fonte: ONG Lajedo curta os Caldeirões, 2014.
Figura 05: Adolfina Pacheco e Emilda Jordão, 1948.

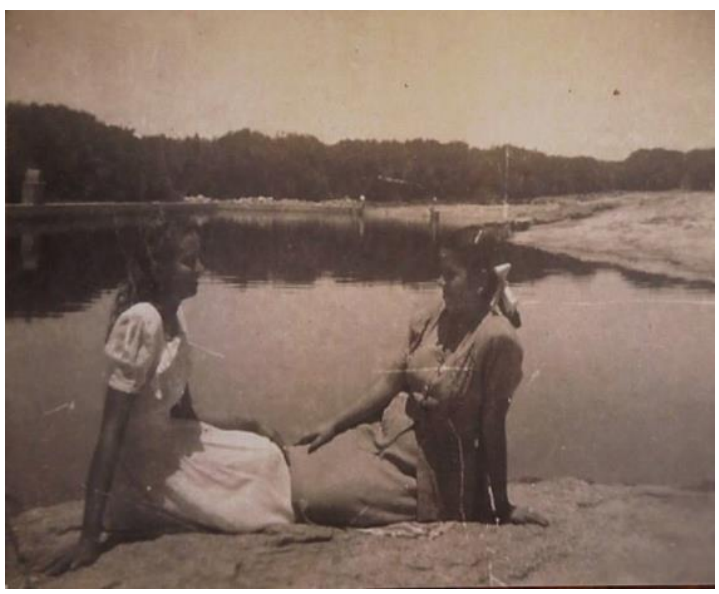

Fonte: ONG Lajedo curta os Caldeirões, 2014.

No entanto, nota-se que depois da década de 1980 quando a Companhia Pernambucana de Saneamento (COMPESA) se instalou na cidade e começou a abastecer o município, a população que necessitava da água dos Caldeirões passou a não depender mais diretamente dessa água, sendo assim, os cuidados para com esse patrimônio foram diminuindo gradativamente, seja por parte da população ou do poder público chegando, então, na atualidade praticamente abandonado, poluído, sujo entre outras mazelas. (Figuras 06 e 07 ).

Figura 06 - Imagem dos Caldeirões de Lajedo - PE

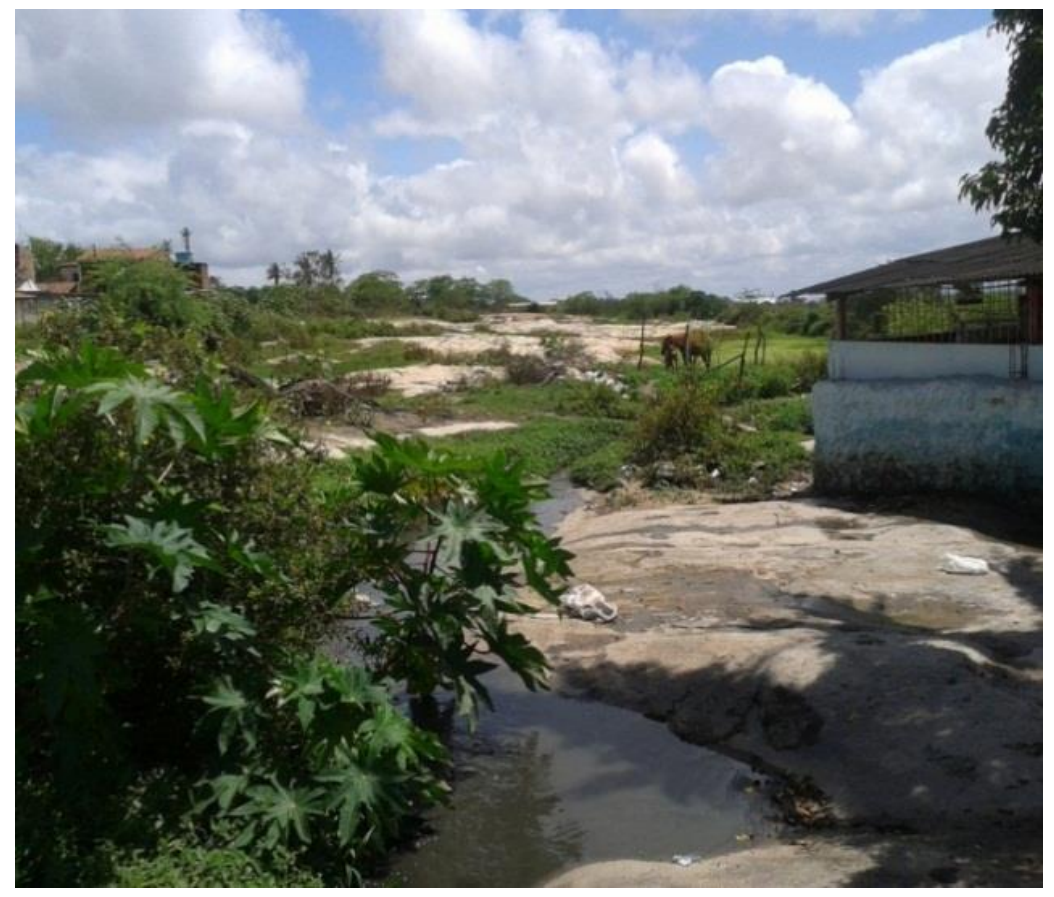

Fonte: Arquivo de J. Lisboa, 2014. 
Figura 07- Imagem dos Caldeirões de Lajedo - PE

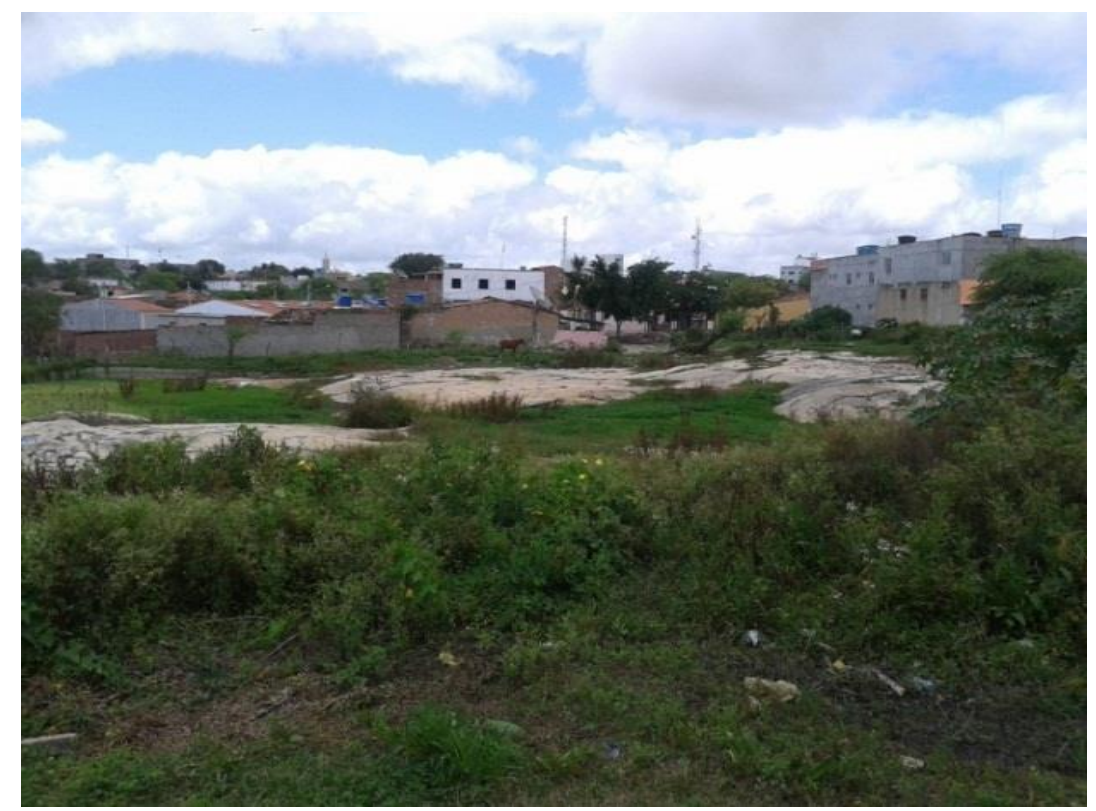

Fonte: Arquivo de J. Lisboa, 2014.

Cabe salientar que quando se observa essas figuras 06 e 07 vê-se a presença de animais soltos, aparentemente sendo criados dentro dos Caldeirões, provavelmente pertence a algum ou alguns moradores do entorno. Também é perceptível a presença de lixo dos mais diversos tipos. Por sua vez, a água pela sua coloração, provavelmente apresenta um índice altíssimo de poluição. Assim fica evidente, diante do exposto, as ações antrópicas estão contribuindo para mudanças na paisagem dos Caldeirões em Lajedo-PE.

\section{CONSIDERAÇÕES FINAIS}

É importante destacar que o trabalho que se apresenta está em fase final de realização e que se vincula a um projeto de maior dimensão que visa estudar compartimentos geomorfológicos no Agreste Meridional de Pernambuco.

Nesse sentido, vale destacar a ideia de sustentabilidade da paisagem geomorfológica do lugar em estudo, visto que a mesma encontra-se com significativos impactos ambientais, bem como proporcionar algum entendimento que possa subsidiar tomadas de atitudes e ações eficazes para que a população reconheça o valor histórico turístico e cultural dos "Caldeirões" e que passe a preservar esse lugar que é dever de todo cidadão incluindo-se, também, a 
população que reside no entorno desse local. Além de que, a conservação do mesmo vai se refletir na saúde e bem- estar desses moradores. Essa ideia pode ser possível através de uma política pública educacional transformadora que desperte nos moradores uma consciência ambiental e o consequente reconhecimento do valor que esse lugar apresenta. Mas, para isso, é necessário que alguns cidadãos conscientes e conhecedores desses problemas trabalhem com o poder público mostrando possibilidades.

\section{REFERÊNCIAS BIBLIOGRAFICAS}

AB'SABER, Aziz Nacib. Os domínios de natureza no Brasil: potencialidades paisagísticas. São Paulo: Ateliê Editorial, 2003.

AMADOR, Maria Betânia Moreira. Abordagem geográfica de antigas áreas algarobadas através do estudo sistêmico dos processos superficiais da paisagem e sua influência na biota local: Monteiro/PR/ - Recife: Ed. Universitária da UFPE, 2013.

Sistemismo e Sustentabilidade: questão interdisciplinar. São Paulo: Scortecci, 2011.

A visão sistêmica e sua contribuição ao espaço pecuário de Venturosa e Pedra no Agreste de Pernambuco, 2008. 316. Tese (Doutorado em Geografia) - Centro de Filosofia e Ciências Humanas. Universidade Federal de Pernambuco, Recife.

O sistêmico e as questões teórico-metodológicas da sustentabilidade no âmbito da geografia. II Fórum Ambiental da Alta Paulista. Tupã, SP: ANAP/FACCAT/UNESP, 2006. 1 CDRom sob o ISSN 1980-0827. Disponível em:

<http://www.amigosdanatureza.org.br/noticias/306/trabalhos/115. AS-8.pdf>. Acesso em: 30 março 2015.

O pensamento de Edgar Morin e a geografia da complexidade. Revista Cientifica ANAP Brasil, n. 2, ano 2 - p. 60-76. 2009.

BERTRAND, G. Paisagem e geografia física global: esboço metodológico. Caderno de Ciências da Terra. São Paulo: USP. 1972.

CASTRO, Cláudio de; JATOBÁ, Lucivânio. Litosfera: minerais, rochas, relevo. 2. ed. Recife: Bagaço, 2006.

CUNHA, Sandra Baptista da; GUERRA, Antônio José (Orgs.) Geomorfologia: exercícios, técnicas e aplicações. Rio de Janeiro: Bertrand Brasil, 1996.

(Org.) Geomorfologia e meio ambiente. 10. ed.- Rio de Janeiro: Bertrand Brasil, 2011.

DIAS, Paulo Henrique. Lajedo: uma história de lutas, conquistas e glórias. Recife: Ed do Autor, 2013.

FLORENZANO, Teresa Gallotti (Org.). Geomorfologia: conceitos e tecnologias atuais. São Paulo: Oficina de Textos, 2008.

HOGAN, Daniel Joseph; Paulo Freire, VIEIRA(Org.). Dilemas socioambientais e desenvolvimento sustentável. 2 ed. São Paulo: Ed Campinas: Editora da UNICAMP, 1995. 
IBGE. Instituto Brasileiro de Geografia e Estatística. 2012 Disponível em: $<$ http://www.censo2012.ibge.gov.br/sinopse/index.php?uf=26\&dados=26>. Acessado em Janeiro de 2015.

JATOBÁ, Lucivânio; LINS, Rachel Caldas. Introdução a geomorfologia. 4 ed. Recife: Bagaço, 2003.

MORIN, Edgar. Introdução ao Pensamento Complexo. Tradução de Eliane Lisboa. Porto Alegre: Sulina, 2005.

MASCARENHAS, João de Castro et al (Orgs.).Projeto cadastro de fontes de abastecimento por água subterrânea. Diagnóstico do município de Lajedo, estado de Pernambuco. Recife: CPRM/PRODEEM, 2005.

SILVA FILHO, J. L.; AMADOR, M. B. M. A Paisagem Geomorfológica dos Caldeirões em Lajedo-PE sob uma Visão Sistêmica do Ambiente. In: Periódico Eletrônico do X Fórum Ambiental da Alta Paulista. Patrimônio Histórico, Turismo e Desenvolvimento Local. v 10, n. 9, p. 92-97, 2014. Disponível em:

http://www.amigosdanatureza.org.br/publicacoes/index.php/forum ambiental/article/view/795/819. Acesso em: 10 de Fevereiro de 2015.

Um Olhar Sistêmico para os Caldeirões no Município de Lajedo-PE. Anais do CBG VII Congresso Brasileiro de Geógrafos, Vitória, ES. ISBN 978-85-98539-04-1. Disponível em: <http://www.cbg2014.agb.org.br/resources/anais/1/1405552057 ARQUIVO ARTIGOAGBUMOLHAR SISTEMICOPARAOSCALDEIROESNOMUNICIPIODELAJEDO-PE.pdf >. Acesso em 05 de Fevereiro de 2015.

SUERTEGARAY, Dirce Maria Antunes. $O$ atual e as tendências do ensino e da pesquisa em geografia no Brasil: Revista do Departamento de Geografia, n. 16, p. 38 - 45, 2005. Disponível em: $<$ http://www.geografia.fflch.br/publicacoes/RDG/RDG 16/Dirce Maria Antunes Suertegaray.pdf>. Acesso em: $11 \mathrm{fev} .2014$.

TUAN, Yi-Fu. Espaço e lugar: a perspectiva da experiência. Tradução de Lívia de Oliveira. Londrina: Eduel, 2013.

. Topofilia: um estudo da percepção, atitudes e valores do meio ambiente. Tradução de Lívia de Oliveira. São Paulo: DIFEL, 1980. 